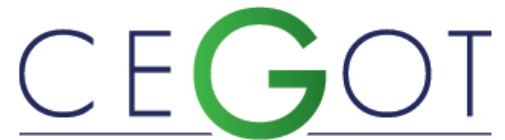

Centro de Estudos de Geografia e Ordenamento do Território
Geografia e Ordenamento do Território, Revista Eletrónica Centro de Estudos de Geografia e Ordenamento do Território http://cegot.org

Portela, Mugiany

Universidade Federal do Piauí, Departamento de Geografia

Campus Universitário Ministro Petrônio Portella - Bairro Ininga, 64048-495,

Teresina, Brasil

mugiany@yahoo.com.br

\section{CAVALCANTI,LANA}

Universidade Federal de Goiás, Instituto de Estudos

Socioambientais

74690-900, Goiânia, Brasil

Is.cavalcanti@uol.com.br

\title{
Contribuições para o ensino de cidade: observação de fotografias em livros didáticos de geografia
}

Contributions to city teaching: a reading of photographs in didactic books

Referência: Portela, Mugiany; Cavalcanti, Lana (2018). Contribuições para o ensino de cidade: observação de fotografias em livros didáticos de geografia. Revista de Geografia e Ordenamento do Território (GOT), n. ${ }^{\circ} 13$ (junho). Centro de Estudos de Geografia e Ordenamento do Território, p. 337-361, dx.doi.org/10.17127/got/2018.13.015

\section{RESUMO}

O cenário da educação brasileira tem caminhado para a adesão cada vez maior do uso do livro didático nas escolas. Nesse intuito, o presente artigo tem como objetivo analisar em que medida as fotografias contidas nos livros didáticos contribuem para a construção do pensamento sobre ensino de cidade. $\mathrm{O}$ alcance desse objetivo se deveu à observação das fotografias e legendas dos livros que pertencem às coleções didáticas mais adotadas pelo Plano Nacional do Livro Didático (PNLD) de 2012, no Brasil. Pode-se constatar que há cidades que aparecem mais vezes, enquanto outras não são representadas nas fotografias, de modo que pode haver um comprometimento da construção do pensamento, especialmente porque muitas cidades presentes nos livros didáticos não fazem parte das vivências cotidianas de muitos jovens que cursam o ensino médio, no Brasil.

Palavras-chave: Ensino. Cidade. Livros didáticos. Fotografias. Geografia.

\section{ABSTRACT}

The scenario of brazilian education has been growing to access increasingly the didactic book usage at schools. Then, this article has as a purpose aimed to analyze how pictures in books contribute to city teaching. The reach of this purpose is given by the observation of the photographs and the subtitles found in didactic books collection more adopted for National Didactic Book Plan (PNLD) 2012, in Brazil. It can be seen that has cities that show up more times, while others are not represented in those photos, this means that may exist a commitment in the thought construction, especially because many cities that are presents in this didactics books are not part of the everyday experiences of many high school students, in Brazil. 
Keywords: Teaching. City. Didactic book. Pictures. Geography.

\section{Introdução}

O livro didático é um dos principais recursos utilizados nas escolas brasileiras. Para grande parte dos professores e alunos, em especial os da rede pública de ensino, chega a ser um manual inquestionável de conteúdos a serem trabalhados, ao ponto de os projetos pedagógicos da escola e dos planos de trabalho dos professores basearem o cotidiano das aulas exclusivamente pelo que está no livro didático.

Impressas nas páginas dos livros didáticos estão, também, questões ideológicas, políticas, culturais, curriculares, pedagógicas, editoriais e comerciais. É, por isso, um objeto de críticas de muitos estudiosos que se dedicam a essa questão, conforme bem apontou Cisternas (2012). Diante dessas funções, o livro didático não deve ser visto apenas como um instrumento que norteia os fazeres e deveres em sala de aula, o que por si só já teria importância, mas também como um objeto que direciona os saberes escolares e, por essa razão, tem auxiliado na construção do pensamento de muitas crianças e jovens.

De acordo com esse raciocínio, como estão sendo construídos os conceitos geográficos nos livros didáticos, especialmente, quando se pensa nos que são atinentes ao ensino de cidade? Em que medida as ilustrações podem contribuir para a construção desses conceitos para os jovens do ensino médio - último nível da educação básica? E, é possível identificar as cidades que mais são vistas e, ao mesmo tempo, as que são excluídas quando se investiga as fotografias dos livros didáticos? Pensando nessas questões, fomentou-se os seguintes objetivos: identificar como o livro didático pode interferir na construção do pensamento sobre cidade; e analisar nas coleções de livros didáticos, o que tem sido abordado sobre cidade e o urbano.

Nesse aspecto, como não seria possível para essa pesquisa realizar uma leitura de todos os livros que foram adotados no Brasil como material didático escolar, optou-se por escolher 
as duas coleções mais adotadas, nas escolas públicas, para o Ensino Médio no ano de $2012^{1}$. A análise foi feita mediante a observação das fotografias veiculadas nos livros e de suas respectivas legendas.

A observação atentou prioritariamente para a leitura das legendas das fotografias. Limitouse a esse critério devido à complexidade que envolve a análise das fotografias (remete a muitos campos disciplinares, para citar alguns: a Semiótica, a Linguística, a Pedagogia e a Ciência da Informação). Por ser um texto que apresenta as impressões dos autores sobre as fotografias, as legendas indicam os conceitos e as associações feitas entre as imagens e os conteúdos. Acredita-se que os leitores dos livros didáticos poderão ser influenciados pelo que foi escrito nas legendas. Desse modo, as fotografias e as legendas são importantes para a construção dos conhecimentos geográficos presentes no livro didático.

Nesse sentido, houve uma discussão geral e introdutória sobre os aspectos urbanos presentes nos livros analisados e, depois, a apresentação da observação das fotografias contidas neles. Foi possível constatar determinadas peculiaridades que contribuem para se entender como pode ter sido construído o pensamento dos jovens sobre as cidades. Desse modo, as coleções analisadas foram: Fronteiras da globalização de Almeida e Rigolin (2010 a, b e c), e Geografia Geral e do Brasil: espaço geográfico e globalização de Sene e Moreira (2013 a, b e c), ambas divididas em três volumes (BrasiL, 2013).

Como não foi objetivo deste trabalho realizar uma comparação entre as coleções de livros didáticos, optou-se por uma apresentação geral, com alguns aspectos pontuais das informações. Assim, organizaram-se as ideias do texto numa análise descritiva e particular às coleções de livros selecionados, com o intuito de refletir e sugerir abordagens para o ensino de Geografia. Ele está, inicialmente, voltado para uma identificação dos autores dos livros didáticos e como as fotografias estão distribuídas por região, embora reconheça-se que as referidas informações têm amplitude maior. Isso porque o ensino de Geografia perpassa diferentes concepções de conteúdos geográficos na escola. Com essa lógica, faz todo sentido pensar o livro didático como parte da cultura escolar, e essa certeza garante afirmar que nenhuma escola funciona sem ao menos uma mínima presença desse recurso didático.

\footnotetext{
${ }^{1}$ Os livros dessas coleções chegaram às escolas em 2013 e, em 2016, teriam fechado o ciclo referente aos três anos do Ensino Médio. Igualmente, esse seria o ciclo completo de três anos mais recente.
} 


\section{O livro didático na escola: contribuições para a construção do}

\section{pensamento}

De acordo com Vigotsky (2000), a construção do pensamento envolve a internalização de conceitos que são mediados pelo ensino do professor na escola. A internalização é uma capacidade cognitiva desenvolvida pelo sujeito, quando consegue construir um conceito científico em suas funções mentais superiores do pensamento. Sobre esse aspecto, Cavalcanti (2012) afirma que deveria ser uma função prioritária do ensino ajudar os alunos a formarem conceitos, nesse caso, os científicos, que são viabilizados pelo ensinoaprendizagem realizado na escola. Nas palavras da mesma autora (2012, p. 158):

O trabalho docente orientado para o desenvolvimento teórico dos alunos se desenvolve buscando estabelecer, com a intervenção deliberada do professor, a relação do aluno com o mundo objetivo. Nessa relação, o aluno desenvolve sua capacidade mental, sobretudo a de formar conceitos, para lidar com o mundo. Ajudar a formar conceitos é, portanto, papel central do professor.

Vale lembrar que as gerações de livros didáticos de Geografia que passaram pelas escolas brasileiras durante seus quase $90^{2}$ anos de existência resultaram de muita luta por parte da sociedade, de forma geral. Essa história carrega alguns respaldos, mas também muitas frustrações resultantes de decisões governamentais fincadas nas adequações de políticas. Paralelamente, as posturas governamentais deixaram suas marcas nos modos como foram produzidos os livros didáticos. Desse ponto de vista, conforme Kimura (2014, p. 22, 23), a respeito da abordagem dos conteúdos dos livros didáticos de Geografia, é possível fazer a seguinte descrição:

Até meados dos anos de 1950, os livros didáticos das várias matérias lecionadas nas antigas escolas primárias [...], ginasiais e colegiais eram livros escritos discursivamente, informando conceitos e temas. Quando

\footnotetext{
${ }^{2}$ Embora o livro didático exista há mais de 90 anos no Brasil, com indícios do século XVIII (Bittencourt, 1993), o programa de distribuição do livro didático no Brasil data de 1929, segundo o Instituto Nacional do Livro - INL. Nesses quase noventa anos, foram sucessivas políticas que tiveram o intuito de ampliar a distribuição de livros, embora em alguns momentos houvesse alguns obstáculos políticos e econômicos. A respeito disso, em 1985, o Decreto no 91.542, de 19 de agosto de 1985, estabelece o Programa Nacional do Livro Didático - PNLD, e em 2003 é publicada a Resolução CD FNDE no 38, de 15 de outubro de 2003, que institui o Programa Nacional do Livro Didático para o Ensino Médio (PNLEM), com execução em 2003. Recuperado de: www.fnde.gov.br/histórico.
} 
muito havia um questionário complementar ao final do capítulo. [...] A partir de fins dos anos de 1950 e mais ainda nos anos de 1960, os livros didáticos passaram a trazer os conteúdos escritos em textos mais coloquiais, entremeados de atividades ao longo dos mesmos. Nos anos de 1970, esse tratamento didático atingiu o apogeu no uso de atividades do tipo palavras cruzadas, verdadeiro/falso, preenchimento de lacunas etc., havendo mesmo livros escritos sob a forma de história em quadrinhos. [...] A partir de meados dos anos 1980, correspondentes ao fim do governo militar no Brasil, vários estados e municípios fizeram suas propostas de ensino, dentre elas, as de Geografia. Elas indicavam o fim da vigência dos Guias Curriculares. [...] Em fins dos anos de 1990, com a implantação dos Parâmetros Curriculares Nacionais pelo Ministério da Educação-MEC, os livros didáticos propuseram-se a implementá-los.

Com a implementação dos PCN, houve uma mudança significativa no estilo em que passaram a ser apresentados os livros didáticos. Adiciona-se o fato dos "inúmeros processos que são desencadeados na educação a partir da escola ou de fora para dentro dela" (Albuquerque, 2011, p. 157). Nesses processos, destacam-se os estudos mais especificamente voltados para a função curricular, a influência na formação inicial, o projeto gráfico e editorial, dentre outros.

Notadamente, na formatação gráfica dos livros didáticos, Tonini (2011) destacou que, a partir das duas últimas décadas do séc. $X X$, as inovações no campo de editoração puderam ser mais bem percebidas, em especial, nos livros de Geografia. O maior impacto se deu pelo uso recorrente de fotografias, gráficos, mapas e outros tipos de ilustração, o que propiciou um novo modo de ler o livro didático. Nas palavras da autora: "Embora muitas vezes meramente como acessórios, não se pode negar a interpelação que exerce junto à geração de jovens estudantes escolares" (Tonini, 2011, p. 148). Mas, de que modo essa nova leitura interfere no aprendizado dos jovens? A autora sugere:

Entender a imagem como um discurso, um elemento disciplinar que tenta fixar um determinado significado como natural. Dessa maneira, tornam-se tão relevantes as indagações iniciais sobre o que se está vendo com o que está sendo produzido como conhecimento da imagem. Examinar a imagem veiculada nos livros didáticos de Geografia como produtora de significados, que utiliza diversas estratégias implicadas em relações de poder para tecer uma malha privilegiada para determinados conhecimentos (Tonini, 2011, p. 153).

A formação de um pensamento geográfico sobre cidades, nessa compreensão, não ocorre exclusivamente quando os professores selecionam os conteúdos em relação ao urbano e à cidade para ministrar algumas aulas, embora esses momentos sejam fundamentais para consolidar uma proposta conceitual desse assunto. Pondera-se que os conceitos em torno 
do que é cidade e urbano estão constantemente associados a outros conteúdos geográficos que propõem o entendimento do cotidiano. Dessa forma, ao observar como as cidades são apresentadas no livro didático, podem-se dimensionar quais abordagens e quais cidades foram possivelmente comentadas em sala de aula pelos alunos e professores e como elas estão associadas a diferentes conteúdos particulares do ensino de Geografia.

Segundo o Censo do IBGE 2010, é nas escolas públicas brasileiras que se concentra o maior número de estudantes do país (Brasil, 2010a). Esses recebem gratuitamente livros didáticos para as disciplinas ministradas na escola. Essa escolha e a distribuição dos livros didáticos ocorrem por intermédio do Programa Nacional do Livro Didático - PNLD. Os critérios estabelecidos para a aprovação dos livros levam em consideração uma formação mínima voltada para a compreensão dos principais conceitos geográficos. Nas concepções estabelecidas pelo PNLD para o ano de 2012, solicitou-se dos autores o cuidado: com as questões alusivas aos diferentes contextos sociais; com a coerência e a adequação metodológica; com conteúdos e conceitos geográficos aceitos pela comunidade científica e aplicados a todas as regiões do país; com ilustrações adequadas e corretas, e outros critérios semelhantemente importantes (Brasil, 2011).

Dessas coleções que foram distribuídas em todo o território nacional, no ano de 2013, as mais adquiridas em termos numéricos foram: Geografia Geral e do Brasil: espaço geográfico e Globalização e fronteiras da globalização (Brasil, 2013). Essas coleções que serão estudadas na sequência contemplam as suas racionalidades didáticas estabelecidas e esclarecidas no material de apoio para o professor. Contudo, é importante sublimar que as descrições, realizadas a partir da leitura dos capítulos dos livros, apresentadas neste artigo têm a intenção de demonstrar indícios de um aprendizado sobre as cidades e os aspectos urbanos. 


\section{A cidade e o urbano nos livros didáticos das coleções}

\section{analisadas}

Os autores da coleção "Geografia Geral e do Brasil", da editora Scipione, João Carlos Moreira e Eustáquio de Sene, têm formação em Geografia, sendo que o primeiro também é graduado em Direito e o segundo autor é bacharel e licenciado em Geografia. Ambos possuem Pós-graduação em Geografia na Universidade de São Paulo - USP. Moreira possui mestrado em Geografia Humana e Sene e doutorado na mesma formação. Os professores têm experiência docente na rede pública e privada de ensino. O professor Eustáquio de Sene assumiu a função de professor de Metodologia do Ensino de Geografia na Faculdade de Educação da Universidade de São Paulo (Sene e Moreira, 2013a). Sobre a coleção escrita por eles, para o PNLD (Brasil, 2011, p. 72):

A concepção teórico-metodológica adotada na coleção tem caráter interdisciplinar e leva em consideração as relações espaço-temporais, bem como as relações entre a sociedade e a natureza. É estimulada a apreensão da realidade contemporânea, a partir das transformações em escala global, que são relacionadas com a vida das pessoas em escala local.

Já, a segunda coleção, "Fronteiras da Globalização", da editora Ática, tem como autores Lúcia Marina Alves de Almeida e Tércio Barbosa Rigolin. Os dois autores são licenciados e bacharéis, formados em universidades localizadas no estado de São Paulo. A primeira autora graduou-se em Geografia pela PUC - SP, e o segundo autor, em História pela USP SP e em Ciências Sociais pela UNESP - campus de Araraquara. Também, os dois têm experiência com ensino fundamental e médio, em escolas públicas e privadas, no estado de São Paulo (Almeida; Rigolin, 2010a). Acerca dessa coleção, o PNLD (Brasil, 2011, p. 36) coloca que:

$\mathrm{Na}$ coleção, o espaço geográfico, entendido como o resultado da interferência humana na natureza, é a principal categoria de análise adotada, ainda que as fronteiras e os contrastes e contradições do espaço tenham sido privilegiados como recursos importantes no desenvolvimento do trabalho com os alunos. Entretanto, o espaço geográfico é tratado, em alguns capítulos, de forma segmentada e descritiva, fazendo com que os conteúdos nem sempre favoreçam o estabelecimento de relações entre os espaços natural, econômico e social.

As duas coleções seguem um desenvolvimento dos conteúdos com conduta semelhante: tratam de uma Geografia mais geral, que aborda os pormenores referentes ao modo como o mundo pode ser representado quanto às características naturais, econômicas e sociais, e 
exploram similares conteúdos de acordo com o espaço brasileiro. Os conteúdos, pela própria proposta curricular nacional, seguem com estrutura pouco diferenciada, se comparadas as duas coleções.

$\mathrm{Na}$ apresentação dos volumes e nos prefácios, as propostas para os livros didáticos encaminham um cenário voltado para a formação cidadã ou uma politização mais consciente dos fenômenos que ocorrem no espaço geográfico. Há a exigência, no PNLD (Brasil, 2011), de que os livros abordem conteúdos correspondentes à proposta nacional.

Nessa medida, por mais que haja o engajamento dos autores dos livros, ocorre pouca ou nenhuma oportunidade de problematização e reflexão sobre as questões urbanas, deixando-se para o final de cada capítulo ou da seção do livro, um conjunto de enunciados de vestibulares, Exame Nacional do Ensino Médio (ENEM) e outros tipos de questões, as possibilidades de os alunos pensarem sobre os assuntos tratados em sala de aula. $\mathrm{Na}$ maioria das vezes, os exercícios têm o objetivo de treinar a habilidade de resoluções de questões em testes que lhes possibilitarão o ingresso em universidades. Por esse prisma, pode acontecer que a autonomia do professor fique comprometida pela cobrança dos sistemas de ensino (público, privado, filantrópico...), no sentido que os docentes desenvolvam suas atividades com vistas a pensar nos testes externos à escola em que trabalha.

Com base nas considerações anteriores, partiu-se para a análise da proposta para o ensino de cidade naqueles livros didáticos.

A primeira coleção, intitulada Geografia Geral e do Brasil: espaço geográfico e globalização (Sene e Moreira, 2013a, b e c), concentra a temática da urbanização no terceiro volume, em uma unidade com dois capítulos: um dedicado ao processo de urbanização em escala global, e outro que apresenta as cidades e a urbanização brasileira. O capítulo que discorre acerca do "espaço urbano no mundo contemporâneo" traz logo no princípio duas questões que funcionarão como "carros-chefe" dos conteúdos a serem desenvolvidos: "O que mudou no espaço geográfico nacional e mundial com a aceleração do processo de urbanização? Quais foram as consequências socioeconômicas mais importantes desse processo?" (Sene e Moreira, 2013c, p. 175). É interessante destacar que os autores tiveram a preocupação de introduzir uma breve problematização, o que ajuda a construir um pensamento. 
Sene e Moreira (2013c) começam o capítulo contextualizando os diferentes tipos e funções das cidades no decorrer da história desde a antiguidade. Além disso, destacam alguns conceitos para a compreensão do processo de urbanização, tais como: os fatores atrativos e repulsivos que motivam a imigração e a emigração de contingentes populacionais para as cidades. Nessa pauta, os autores foram criteriosos ao apontar a relação da industrialização com a urbanização, o que pode ser verificado nesse trecho do livro:

Isso ocorre porque o fenômeno industrial, sobretudo em seu início, não se desvincula do urbano. Com exceção da China e da Índia, com as maiores populações do planeta e de industrialização recente, todos os países industrializados apresentam taxas de urbanização relativamente elevadas (Sene e Moreira, 2013c, p.179).

Conjuntamente, os autores explicaram, em pormenores e com exemplos, os aglomerados urbanos (metrópoles, megalópoles) e os principais problemas sociais urbanos, comuns às cidades no mundo, os quais estão associados às moradias sem infraestrutura e à violência urbana como reflexo das desigualdades e segregação socioespaciais. Citam diferentes cidades, em países desenvolvidos, em desenvolvimento e subdesenvolvidos para exemplificar as diversas situações de precariedade no modo de vida, o que inclui a habitação e os serviços disponíveis às pessoas. Para fechar o capítulo, tratam da rede e hierarquia urbana e das cidades globais.

Logo, no capítulo seguinte, abordam "As cidades e a urbanização brasileira". Os autores começam por definir o que seria uma cidade e argumentam que classificar uma cidade no Brasil envolve pensar nas particularidades e nos contextos sociais em que vivem as populações em diferentes estados brasileiros. Porém, há algumas informações que são comuns a todas as cidades, tais como: "densidade demográfica, número de habitantes, localização e existência de equipamentos urbanos, como comércio variado, escolas, atendimento médico, correio e serviços bancários" (Sene e Moreira, 2013c, p. 195).

Além disso, é bem oportuno o posicionamento dos autores a respeito da divisão em perímetro urbano e rural feita pelo IBGE. Segundo Sene e Moreira (2013c), no Brasil, por causa dessa classificação, atribui-se o uso do espaço a lugares que mais se assemelham, 
pelas suas características, às áreas rurais, mas que, por razões relacionadas a impostos prediais urbanos (IPTU) ${ }^{3}$ e questões políticas, estão inseridos no perímetro urbano. ${ }^{4}$

Os autores apresentam de modo igual, nesse capítulo, uma organização do processo histórico de urbanização do território brasileiro, por meio de quatro períodos: o primeiro vai até a década de 1930; o segundo, a partir de 1930; o terceiro, entre as décadas de 1950 e 1980; e o quarto, de 1980 aos dias atuais. A separação em períodos considerou os processos de migração regional, a dispersão das atividades econômicas, a infraestrutura de transportes e telecomunicações, estruturação da rede urbana brasileira, o crescimento das metrópoles regionais e cidades médias. Além do mais, os autores ampliam os conteúdos referentes às regiões metropolitanas brasileiras, o que inclui as RIDES; ${ }^{5}$ a hierarquia e influência dos centros urbanos no Brasil; e a importância dos planos diretores e outras regulamentações legais que interferem no gerenciamento das cidades (Sene e Moreira, 2013c). A unidade "O espaço urbano e o processo de urbanização" termina com a sugestão de pesquisas em outros tipos de fontes, tais como filmes, sites e livros.

Na outra coleção, Fronteiras da globalização (Almeida e Rigolin, 2010 a, b e c), cada volume desenvolveu uma abordagem geográfica. O volume 1 tem como objeto "O mundo natural e o espaço humanizado". O volume 2 abordou "O espaço geográfico globalizado" e o volume 3, "O espaço brasileiro e trabalho". Observou-se que a temática "cidade e urbano" é desenvolvida de maneira mais direta nos volumes 1 e 3, apesar de o segundo volume versar sobre vários aspectos concernentes às cidades com feição mais ampla.

O volume 1 aborda alguns dos principais conceitos da ciência geográfica, tais como: lugar, paisagem, espaço geográfico, território, territorialidade, globalização. Também expõe os princípios de localização geográfica por meio das representações cartográficas e as medidas de tempo no espaço geográfico; aponta as dinâmicas da natureza pelas paisagens mundiais, e o que mais simboliza as condições geológicas, climáticas e ambientais que favoreceram a

\footnotetext{
${ }^{3}$ Grande parte das residências pertencentes à área urbana de um município estão sujeitas ao pagamento do IPTU, tal contexto gera mais receita para o poder municipal.

${ }^{4}$ Lembra-se que no Brasil mais de 2.500 munícipios do total de 5.565 possuem até, no máximo, 10.000 habitantes (BRASIL, 2010b).

${ }^{5}$ As RIDES constituem-se como uma forma de construção de redes de cooperação, por envolver municípios de mais uma Unidade da Federação. A Ride é uma forma de ação mais ampla que a prevista nas regiões metropolitas. No Brasil, são três: RIDE-DF (municípios de Goiás, Minas Gerais); RIDE Grande Teresina (municípios do Piauí e Maranhão); e RIDE Petrolina-Juazeiro (municípios da Bahia e Pernambuco). Recuperado de: $\underline{w w w}$ mi.gov.br.
} 
formação de um espaço, claramente denominado no livro de natural. Na unidade que versa sobre um espaço humanizado, a temática de urbanização aparece, com realce para uma escala de análise mais global.

O capítulo que aborda o processo de urbanização trata-o com a perspectiva da escala mundial. Começa por tentar definir o que seria cidade e usa, como exemplo, o critério da Organização das Nações Unidas - ONU -, o qual considera um aglomerado urbano somente o local com 20 mil ou mais habitantes. Explica que esse critério pode variar de acordo com o país. Depois, continua a construção do raciocínio do conceito de cidade e utiliza como parâmetros o tipo de sítio e solo urbano, as relações econômicas e sociais desenvolvidas nas cidades e, por fim, conta como, historicamente, têm sido formadas as cidades. Nesse âmbito, assume que houve uma "evolução do fenômeno urbano".

Há de se ter cautela quanto ao uso da expressão "evolução do fenômeno urbano", sobretudo no que diz respeito ao tipo de conceito que se quer colaborar para que os jovens tenham a respeito de cidade. É preciso considerar que nenhuma cidade, por mais que tenha características em comum, se assemelha integralmente a outra. Admite-se, assim, que toda cidade é ímpar. Entretanto, ao usar a palavra evolução, pode-se compreender erroneamente que as cidades seguirão um caminho habitual, costumeiro a toda e qualquer cidade.

De certa forma, quando os autores apresentam os marcos históricos e as funções que as cidades exerciam para um dado contexto, ou quando apontam apenas o papel da indústria como fator que marcou a consolidação dos espaços urbanos, como observado na frase "o processo de industrialização original, também chamado de Revolução Industrial, foi o grande responsável pelo início da urbanização nos países desenvolvidos e em escala mundial" (Almeida e Rigolin, 2010a, p, 207), acabam por deixar uma informação pendente de acabamentos. Têm-se, por exemplo, para ampliar a informação, questões norteadoras, como: de que forma explicar essa frase em cidades que não tiveram o processo industrial como marco para a consolidação urbana? Esperava-se a reflexão de que, embora tais fatos tenham sido notáveis, não há uma certeza evolutiva de que esse fenômeno aconteceu, linearmente e da mesma forma, em todo o mundo. 
Ainda sobre o referido capítulo do livro, consideram-se os conceitos de desenvolvimento e de subdesenvolvimento, e os seus reflexos nas áreas urbanas. Nesse sentido, destaca-se o crescimento populacional nas cidades como consequência da busca por melhores oportunidades de trabalho, estudo e condições de vida. Apontam os problemas urbanos (trânsito caótico, diferentes poluições, violência, custo de vida alto e outros) como algo corriqueiro em cidades de países em desenvolvimento e esclarecem que alguns desses problemas são comumente encontrados também nos países desenvolvidos.

Os autores seguem o capítulo com a abordagem dos conceitos de urbanização, crescimento urbano, conurbação, metrópoles, megacidades, e finalizam expondo a hierarquia e rede urbanas. Corrobora-se que foi oportuna a apresentação de uma outra possibilidade de classificação das cidades, ou seja, uma que leva em consideração outros critérios, além do número de habitantes. No caso, falou-se dos serviços e do papel que esses desempenham nas cidades-centros, possíveis de serem encontradas no Brasil e em outros países do mundo.

Contudo, ao concluir o capítulo, após seguidas definições, os autores assim se referem: "A rede urbana brasileira tem como principal característica as disparidades regionais, pois enquanto é bem articulada no Sudeste, o mesmo não ocorre nas regiões Norte e CentroOeste" (Almeida e Rigolin, 2010a, p. 210). Nessa citação, pode-se identificar algumas questões: por que aludir à temática "região" sem uma contextualização adequada de como se aplica nesse caso? Em que sentido é promissor citar as regiões brasileiras como estruturantes de uma rede e depois não continuar no capítulo seguinte a discussão dessa questão?

Na realidade, os conteúdos que envolvem a geografia do Brasil somente são retomados no volume 3 da coleção (Almeida e Rigolin, 2010b), o que significa que os conceitos relativos ao processo urbano brasileiro não predominam no volume 2 . Se os alunos estudarem apenas essa coleção no Ensino Médio, terão acesso aos estudos geográficos que remetem ao Brasil somente no último ano da educação básica, o que pode resultar num aprendizado estanque, sem uma devida contextualização.

No volume 3 da coleção, são expostos os conteúdos concernentes ao espaço brasileiro. Das seis unidades, a primeira volta-se para as questões mais físicas do espaço geográfico, 
denominada pelos autores de "espaço natural"; a terceira, a quarta e a quinta unidades discorrem acerca dos setores econômicos: atividades primárias, secundárias e terciárias; a sexta unidade detém-se à explicação dos impactos ambientais no território brasileiro. Somente na segunda unidade, há um capítulo que remete ao processo de urbanização no Brasil. Semelhantemente ao formato do volume 1, esse capítulo está na unidade que explora a ocupação territorial pela população. Há, no entanto, diferença na escala de análise, pois o primeiro volume apresenta a população mundial e o terceiro volume, a população brasileira.

O capítulo que trabalha a urbanização das cidades brasileiras é intitulado "Processo de urbanização no Brasil" e começa por repetir a definição da ONU de cidade, conforme o volume 1. Novamente relaciona-se exclusivamente, sem intermediação de outros aspectos, o processo de urbanização ao processo de industrialização e é traçada uma proposta de divisão de hierarquia urbana. Para tanto, os autores recorrem à organização por regiões de influência das cidades, desenvolvida pelo Instituto Brasileiro de Geografia e Estatística IBGE. Essa organização atribui níveis, subníveis e características para a rede urbana brasileira.

Nesse capítulo, outra vez, são colocadas as definições: de sítio urbano e o tipo de relevo em que este pode ser edificado; dos tipos de cidades, como as que são planejadas; das áreas metropolitanas brasileiras; e finaliza por expor os problemas das cidades brasileiras, os quais seriam os de origem social, como o aumento de favelas que ocupam áreas de mananciais e florestas e que, por provocar o desmatamento das encostas, põem em risco a vida de muitas pessoas. Também por causa das favelas, há problemas na rede de esgotos, na coleta de lixo, de água encanada, de falta de energia elétrica e outros, cuja razão, segundo os autores, estaria no fato de que grande parte dos serviços é insuficiente ou clandestina. Mas será que esses problemas são exclusivos das favelas? Pela apresentação do texto, há uma forte tendência a pensar que sim - o que não é verdade. ${ }^{6}$

A coleção dos autores Sene e Moreira (2013a, b e c) apresenta de forma mais contextualizada a relação entre as fotografias, as legendas e os conteúdos, em comparação

\footnotetext{
${ }^{6} \mathrm{Em}$ muitas cidades brasileiras, algumas áreas que possuem os solos urbanos mais caros também são penalizadas pela precariedade de serviços, assim como há também favelas localizadas em áreas próximas às residências luxuosas das cidades que se beneficiam de alguns serviços, por essa razão (IBGE, 2010 b).
} 
com a coleção dos autores Almeida e Rigolin (2010a, b e c). Suas legendas costumam conter mais informações sobre os aspectos possíveis de serem verificados pelos alunos. Ressalta-se que, na primeira coleção, as questões urbanas são desenvolvidas de forma mais dialética, o que pode estimular os leitores a problematizarem e construírem conhecimentos correlatos à produção do espaço urbano, aos problemas e contextos diversos das cidades. Contudo, as explicações contidas nas legendas, na primeira coleção, podem incorrer no risco de uma redução das possibilidades de interpretação das fotografias, haja visto que há poucas problematizações no texto dessas legendas, em detrimento do predomínio da descrição das imagens. Já a segunda coleção apresenta legendas mais simplificadas para as fotografias e faz pouca relação das mesmas com o texto e, quanto aos conceitos, são apresentados de forma muito pragmática, com poucas problematizações.

Em ambas as coleções, os leitores dos livros didáticos terão ao seu alcance um repertório farto de imagens, mapas, tabelas, quadros e sugestões de acessos a sites, livros, filmes, documentários que poderão auxiliar na compreensão de um dado conteúdo. Dessa forma, os processos cognitivos são propostos, o que pode contribuir para a inventividade, análise, criticidade, estímulo a novas problemáticas e formulação de novos conceitos.

Desse modo, indaga-se o seguinte: como as fotografias expostas nos livros analisados podem ter contribuído para o pensamento dos jovens do ensino médio?

\section{A cidade vista pelas fotografias contidas nos livros didáticos analisados}

Para Vygotsky (2000), a linguagem é fundamental para a construção do pensamento, que se dá, dentre outros tópicos, pelo entendimento do signo. O signo pode ser compreendido, também, pela leitura de imagens e pelo que, nesse estudo, os significados das legendas têm a dizer. São elas que podem contribuir para informar sobre um dado lugar e contextualizamno de acordo com o que se pretende explicar aos leitores. Por essa razão, pode-se afirmar que as imagens contidas nos livros didáticos das coleções analisadas podem fornecer fortes 
indícios do que foi ensinado aos jovens. Nessa análise, cabe a leitura das transcrições referentes às ilustrações contidas nas coleções, de acordo com o PNLD:

\section{Coleção Fronteiras da globalização}

A maioria das ilustrações é adequada ao alcance dos objetivos propostos e auxilia na compreensão e reflexão dos temas tratados. As fotografias possuem grande potencial de problematização, pelo conteúdo crítico que apresentam, especialmente por mostrarem contrastes existentes na paisagem. As representações cartográficas e ilustrações contribuem para a visualização e espacialização de fenômenos, cumprindo o papel de auxiliar na leitura e compreensão da realidade representada (Brasil, 2011, p. 3738).

\section{Coleção Geografia Geral e do Brasil}

As ilustrações que compõem as unidades e os capítulos têm grande importância para a legibilidade dos conteúdos. Nesse âmbito, destaca-se a inserção inovadora de infográficos para a compreensão dos fenômenos geográficos e a criatividade das atividades complementares contidas no Manual do Professor. A qualidade do projeto gráfico, dos instrumentos técnicos utilizados para indicação das representações cartográficas, assim como da linguagem escrita (e também de outros gêneros textuais) ao longo de todo o texto, também é um ponto de realce na coleção (BRASIL, 2011, p. 73).

É relevante compreender o uso de imagens, gráficos e outros recursos visuais utilizados com frequência nos livros didáticos e pelos professores no dia a dia de sala de aula. Para Novaes (2017, p. 149), ao parafrasear Barthes $(1971,1990)$, o verbal e o visual estão no livro didático nas "legendas das fotografias e dos mapas... como 'teleguia' em direção a um sentido escolhido a priori, restringindo as opções de interpretações do leitor".

Nesse entendimento, na análise dos seis livros, foram encontradas aproximadamente 2.560 figuras distribuídas em: fotografias (31,5\%); mapas (22\%); ilustrações explicativas, tais como desenhos que comentam as dinâmicas do relevo, clima e outros (18\%); gráficos (16\%); e quadros e tabelas (juntos: 12,5\%). Noutros termos, são as fotografias que estão mais presentes nesses livros didáticos, sendo que, do percentual de $31,5 \%$ de fotografias, $11,5 \%$ correspondem às imagens cuja legenda referia-se a alguma cidade, o que constitui uma boa representatividade.

Dessa maneira, 293 fotografias de diferentes cidades do mundo foram encontradas, conforme descrição de suas legendas, as quais serviram para exemplificar distintos contextos geográficos, desde os mais ligados a problemáticas naturais e ambientais, até aos 
que indicavam as situações socioeconômicas, culturais e religiosas dos povos, o que pode ser observado na Figura 1.

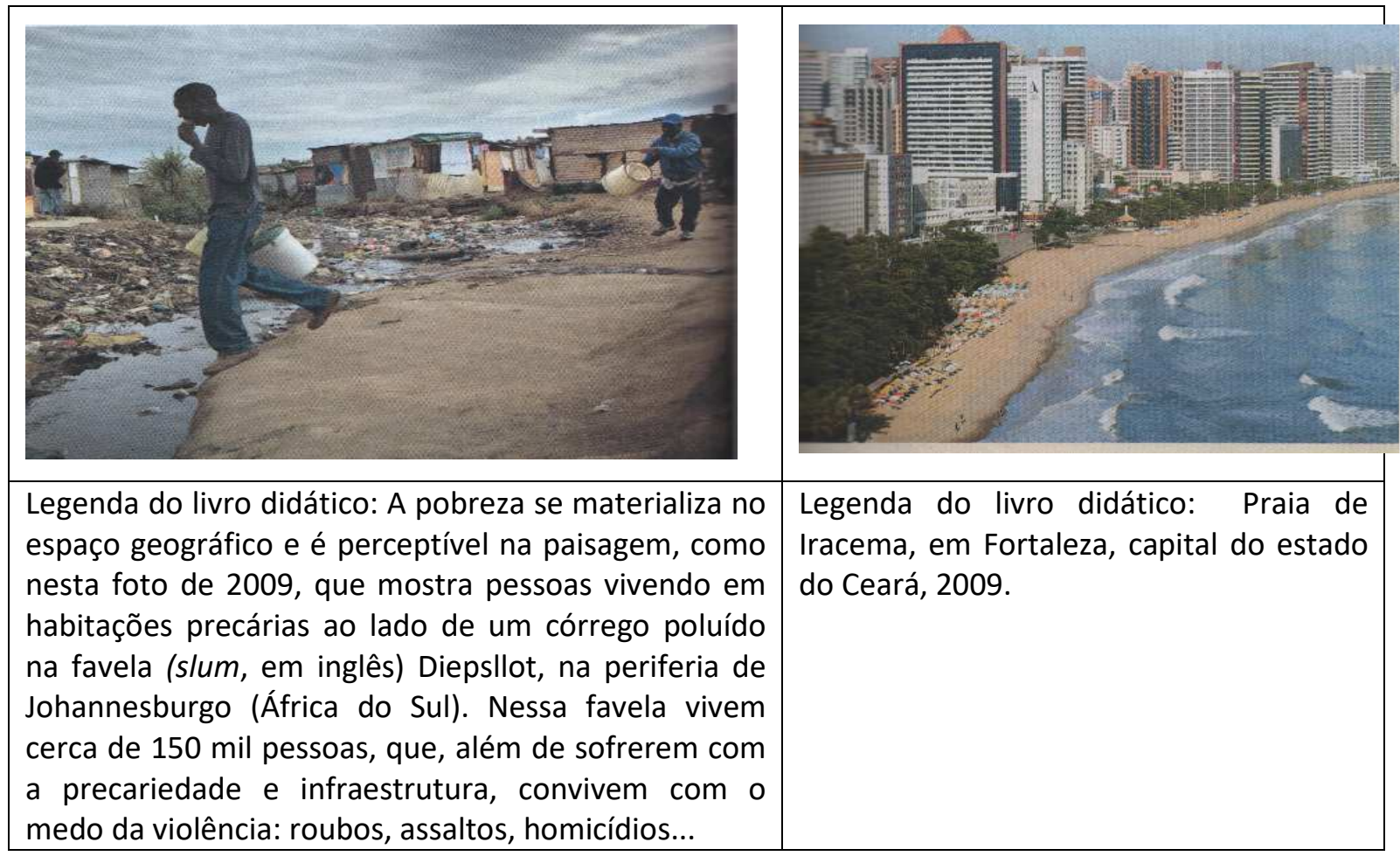

Figura 1 - Exemplos de fotografias com suas respectivas legendas nas coleções de livros didáticos analisadas (Portela, 2017, p. 99)

Pode-se constatar que há uma distribuição desigual de fotografias de cidades, no sentido de representar as cidades brasileiras e as de outras partes do mundo. Para destacar essa disposição, organizou-se a figura 2, que aponta uma distribuição de cidades por regiões no mundo, construída pelas informações coletadas nas legendas das fotografias.

Conforme a figura 2, 44,8\% das fotografias são representações de cidades da América do Sul, contudo, $42,8 \%$ são de cidades brasileiras, mais claramente representadas na figura 3 , que apresenta um mapa do Brasil com a distribuição das fotografias por região.

Destacaram-se a capital São Paulo e outras cidades paulistas, na figura 3, por serem as cidades que mais aparecem, quando se trata de cidades brasileiras. Desse modo, 12,9\% correspondem às cidades do estado de São Paulo. Nesse caso, 7,8\% referem-se à capital do estado, 5,1\% a outras cidades paulistas - São Bernardo do Campo, São José dos Campos, Piracicaba, Campinas, Mongaguá, Caeiras, Jaguariúna, Guarulhos, Guarujá, Campos do Jordão, Cubatão e Sorocaba. Das cidades representadas, $8,2 \%$ são fluminenses, sendo que a capital, Rio de Janeiro, obteve maior representatividade, com 4,4\%. As demais foram: 
Búzios, Angra dos Reis, São Gonçalo, Ilha Grande e Niterói. Também, no Sudeste, as cidades mineiras de Belo Horizonte, São João Batista e Fronteira tiveram fotos nos livros. Essas, com a representação de $2,7 \%$.

Nessa estimativa das cidades brasileiras, estão também as cidades nordestinas, com 8,5\%. As que mais aparecem são as cidades baianas Salvador, Camaçari, Juazeiro, Mataripe, Porto Seguro, seguidas das cidades pernambucanas Recife, Petrolina e Triunfo. As cidades do Ceará: Fortaleza, Jijoca de Jericoacoara e São Gonçalo do Amarante, bem como as cidades potiguares Natal e Macaíba, a cidade paraibana de João Pessoa e a cidade maranhense de São Luís também foram representadas.

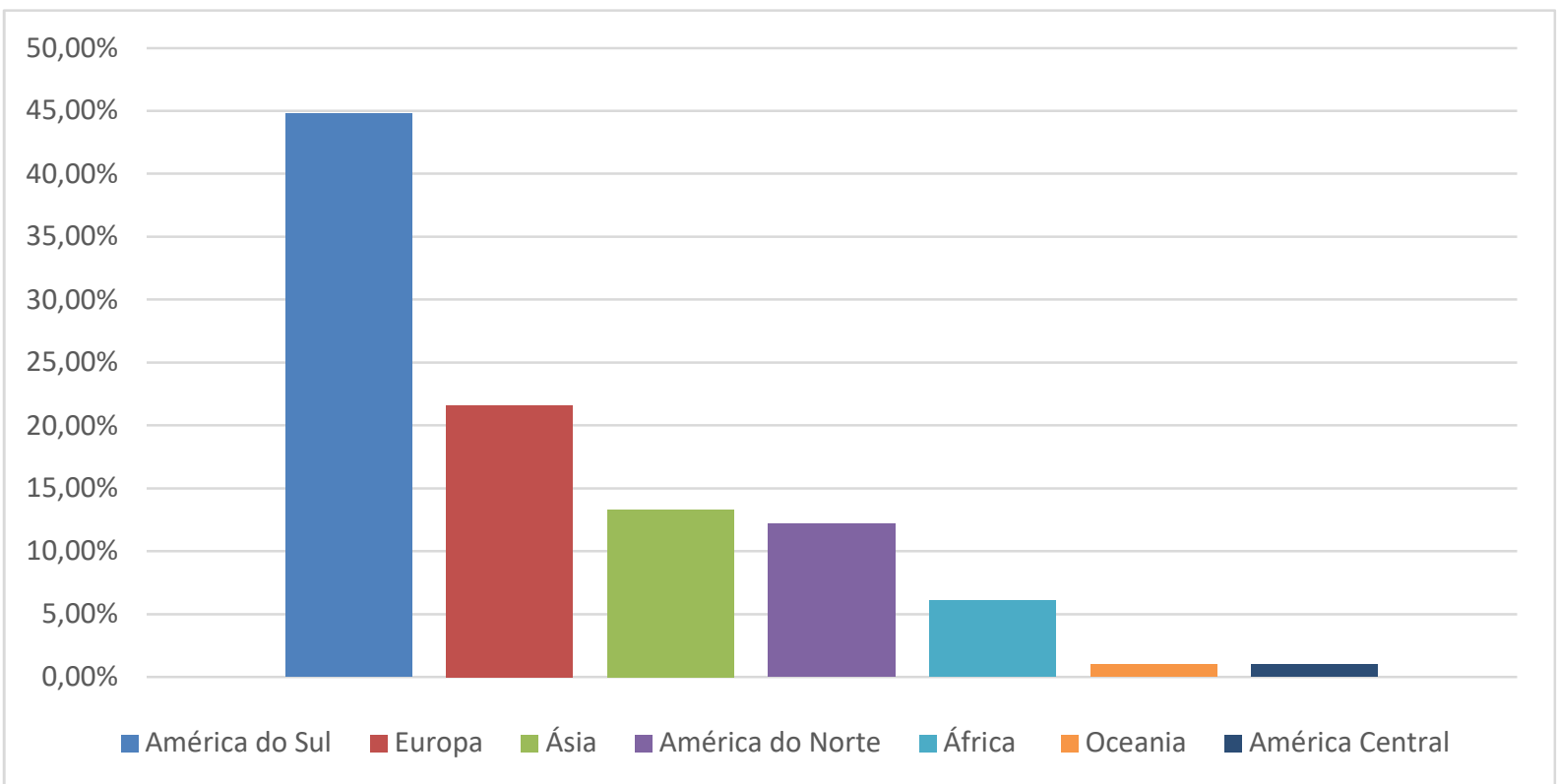

Figura 2: Lugares do mundo em que as cidades são mais representadas nos livros didáticos analisados (Portela, 2017, p. 100).

As cidades do Sul representaram 5,1\%. Dentre as do estado Rio Grande do Sul -RS, estão Gramado, Santana do Livramento, Canoas e Novo Hamburgo; no estado do Paraná-PR: Curitiba, Londrina, Campos Mourão e São José dos Pinhais; e em Santa Catarina: Florianópolis, Capiviri de Baixo, Joinville, Blumenau e São Joaquim. As cidades pertencentes à região Norte (com 3,7\%) foram, no Amazonas-AM: Manaus, Parintins e Tabatinga; no Pará-PA: Belém, Altamira, Cachoeira do Arari, e a cidade de Rio Branco, no Acre-AC e Palmas, no Tocantins-TO. Quanto ao Centro-Oeste $(1,7 \%)$, apenas foram catalogadas as fotografias de Brasília, DF, e Corumbá, Mato Grosso do Sul-MS. 


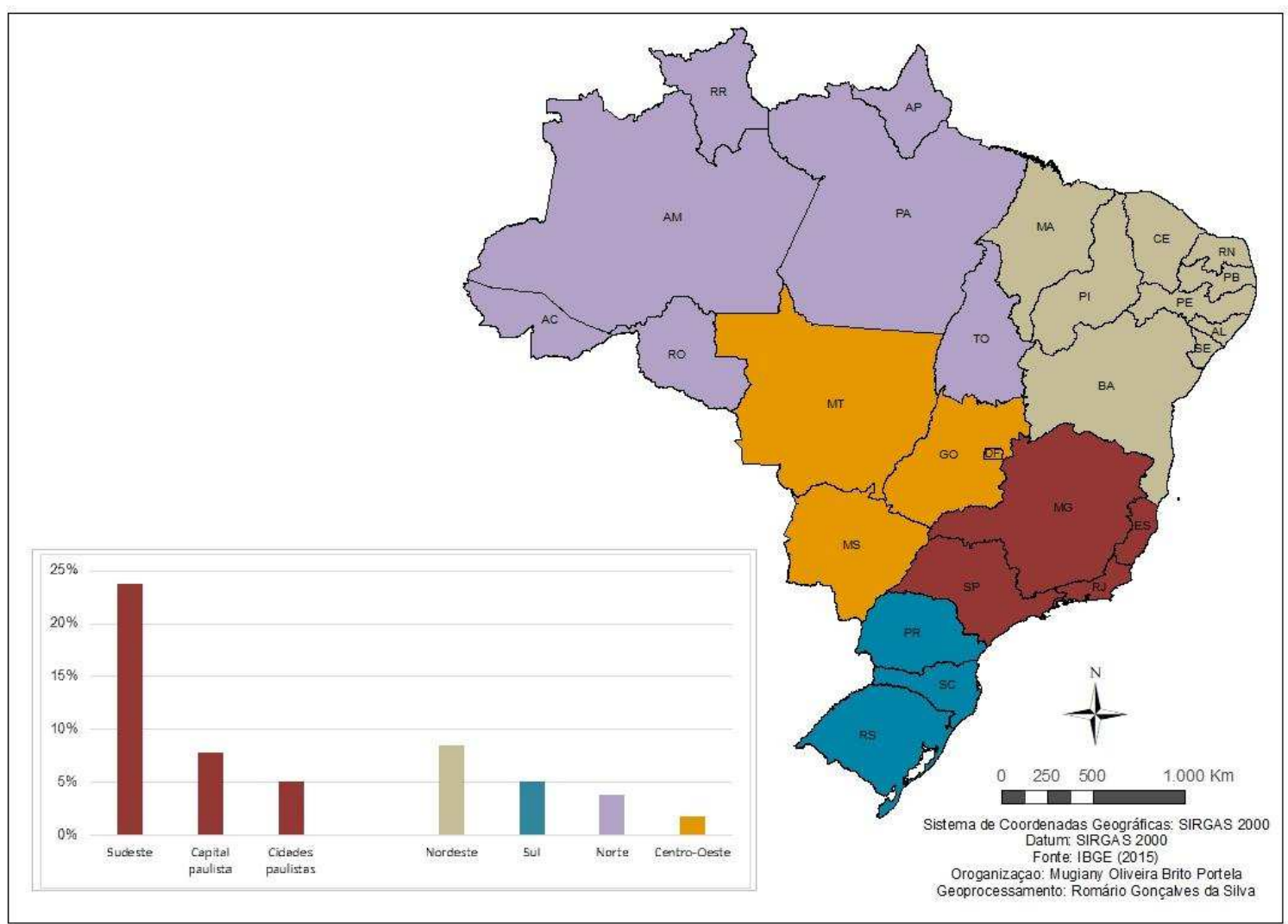

Figura 3: Regiões brasileiras em que as cidades são mais representadas nos livros didáticos analisados (Portela, 2017, p. 101).

Ao examinar as legendas das fotografias das diferentes cidades brasileiras, percebeu-se que as paulistas, em geral, estão associadas às áreas industrializadas, informatizadas e modernizadas pelo setor imobiliário. A cidade de São Paulo aparece representada como possuinte de um setor financeiro fundamental para as decisões econômicas no Brasil, com muitos espaços transformados que se assemelham às cidades de países desenvolvidos, embora também haja fotografias que mostrem os problemas urbanos, os relativos à falta de infraestrutura, aos problemas ambientais, às favelas em áreas de ocupação, e outros atinentes aos impactos negativos sobre o meio ambiente, sobretudo quando se destacam os problemas concernentes à poluição, à inversão térmica e ao descaso com os rios e matas.

As demais cidades da região Sudeste também apontam características semelhantes às cidades paulistas, com a exceção das cidades fluminenses, a que pode ser acrescentada a importância do turismo, as práticas esportivas da população e alguns elementos das paisagens naturais, como as praias e relevos. Outro apontamento é que, em ambas as coleções, quando se fala sobre as questões relativas à energia nuclear, usa-se o exemplo da 
cidade de Angra dos Reis, no Rio de Janeiro, e quando se quer citar a extrema poluição, usase o exemplo da cidade de Cubatão, São Paulo. Os traços mais históricos ligados à formação da população brasileira e estruturação do Brasil remetem às fotografias do Presidente Juscelino Kubistchek em diferentes inaugurações de obras pelo estado de São Paulo, que favoreceram a instalação de muitas fábricas de automóveis.

As cidades da região Sul são apontadas como lugares que conservam muitos traços do período em que o Brasil recebeu vários migrantes de países europeus. Como nessas cidades estão as mais baixas temperaturas do Brasil, vez por outra, as fotografias colocam o dia a dia das pessoas convivendo com o frio. Também há fotografias de situações extremas, como deslizamentos de terras e enchentes. Quanto ao Centro-Oeste, nos seis volumes foram notadas quatro fotografias da cidade de Brasília, no Distrito Federal, que fazem referência aos atos políticos e ao fato de ser uma cidade planejada, além de uma fotografia de Corumbá, no Mato Grosso do Sul-MS, que mostra um casario histórico.

As cidades nordestinas são apresentadas, ora para demonstrar algum aspecto mais ligado aos fatores naturais, a exemplo de Salvador, Bahia-BA, edificada em uma falha tectônica que divide a cidade em dois níveis, a Cidade Alta e Cidade Baixa, ora para mostrar aspectos mais econômicos, como as indústrias de médio e pequeno porte. Para a cidade de Natal, Rio Grande do Norte-RN, as fotografias representam a indústria e o processo de migração. Os desafios das desigualdades sociais, como as casas de palafitas em São Luís, Maranhão-MA, e outras situações de pobreza, também estão presentes. Por outro ângulo, nas fotografias das cidades nordestinas predominou o realce às praias como a de Boa Viagem, em Recife, Pernambuco-PE, a de Iracema, em Fortaleza, Ceará-CE, e a do Ponta do Seixas, em João Pessoa, Paraíba-PB. Não foram encontradas fotografias das capitais Maceió, em Alagoas-AL, Teresina, no Piauí-PI, e Aracaju, em Sergipe-SE.

Com a observação das fotografias e das suas respectivas legendas, pondera-se a predominância de conceitos generalizados das cidades brasileiras. Para exemplificar, as cidades localizadas no Norte do país, de acordo com as imagens, caracterizam-se como locais com poucos serviços e equipamentos urbanos, as cidades do Nordeste despontam pelo potencial turístico, as cidades do Sul são as que exemplificam o cotidiano de brasileiros descendentes de imigrantes e a metrópole paulista é a produtora industrial do Brasil. Claro que há muito mais para se estudar sobre as cidades em suas particularidades e esse é o 
principal desafio - conhecer e publicizar os estudos geográficos sobre as cidades, para que haja uma construção do conhecimento geográfico capaz de relacionar o que acontece nas cidades de vivência dos alunos com os distintos contextos urbanos do Brasil e do mundo.

As cidades pelo mundo também são divulgadas nos livros didáticos. Do que foi coletado de informações, depois das cidades brasileiras, as que mais aparecem nos livros didáticos são as cidades europeias, com 21,7\%, e, destacadamente, as localizadas na Alemanha, França e Inglaterra. Outras cidades localizadas na Bósnia-Herzegovina, Mônaco, República Tcheca, Itália, Bélgica, Espanha, Rússia, Croácia, Albânia, Lituânia, Áustria, Itália, Suíça, Bielorrússia, Grécia, Eslovênia, Suécia, Ucrânia e Romênia também foram representadas nas fotografias.

Nessas cidades, predominaram nas legendas explicativas das fotografias alguns contextos distintos, dentre os quais o de que o continente europeu guarda muitas edificações históricas e muitos prédios que simbolizam os tempos modernos. Isso faz com que grande parte das fotografias de cidades europeias esteja vinculada à narrativa histórica do lugar e seus significados para o local e o mundo. As fotos de Moscou, para exemplificar, servem para representar o socialismo, assim como a emblemática foto da queda do muro de Berlim em 1991, que mostra o fim do Segundo Mundo. Algumas outras fotos são de encontros entre os líderes mundiais envoltos de propostas que decidiram os rumos da economia mundial. Também é possível ver fotos de manifestações populares em prol de melhorias sociais. Cabe destacar as imagens que refletem o envelhecimento da população e os estilos de vida, em sua maioria, com poucos problemas econômicos, quando comparadas às fotos dos problemas sociais do Brasil, por exemplo. Nessas coleções, o problema da migração, atualmente um dos grandes desafios da Europa, somente foi apresentado na Rússia.

Ainda sobre as fotografias, $13,3 \%$ são de cidades da Ásia, sendo as cidades chinesas Pequim e Xangai e a japonesa Tóquio as mais citadas. Além disso, foram colocadas fotografias das cidades pertencentes às Coreias do Norte e do Sul, à Indonésia, à Arábia Saudita, a Cingapura, à Índia, ao Vietnã, a Taiwan, a Bangladesh e ao Uzbequistão. As cidades asiáticas são representadas pelos hábitos culturais, estilo de vida muito vinculado às tradições dos antepassados, à longevidade, às culturas religiosas, à intensa urbanização, ao grande contingente populacional, à importância para a economia global, aos problemas ambientais, aos conflitos religiosos e, ao mesmo tempo, aos avanços tecnológicos e industriais, 
principalmente quando se apresentam Tóquio, no Japão, Pequim, na China, e alguns dos chamados "Tigres Asiáticos”: Cingapura, Coreia do Sul e Taiwan.

As cidades da América do Norte correspondem a 12,2\% das cidades apresentadas em fotografias nos livros escolhidos. A cidade de Nova York nos Estados Unidos foi a mais mencionada nas fotografias. Essa cidade aparece como sede de uma megalópole, como detentora das maiores bolsas de valores do mundo, cidade onde são tomadas as mais memoráveis decisões para a economia global. Outras cidades dos Estados Unidos foram vistas, tais como: Flórida e São Francisco, na Califórnia; Houston e Dallas, no Texas; Washington, DC; Marshalltown, em lowa; San Jorge e Palo Alto, na Califórnia; Pittsburgh, na Pensilvânia; Detroit, em Michigan; Cambridge, em Massachusetts; e Liden, em Nova Jersey. Ainda sobre a América do Norte, a cidade de Toronto foi apresentada como a maior cidade canadense; e as cidades de Tijuana e Cidade do México como lugares de tensão. Ressalta-se a primeira como local em que há migração clandestina e a segunda como foco de protestos populares.

As cidades africanas, com uma representatividade de cerca de $6 \%$ das fotografias, foram quase sempre associadas à pobreza; falta de cuidados necessários à saúde e à educação para as crianças; conflitos internos; cultura e religiosidade; favelas; péssimas condições de moradia; contraste entre as cidades africanas e as de países desenvolvidos; refugiados; ajuda humanitária; e poluição. Mostrou-se, em raras exceções, que nas cidades africanas é possível encontrar pontos turísticos que atraem pessoas de todo o mundo, sendo que as destacadas foram: Nairóbi, no Quênia: Monróvia, capital da Libéria: Sharm El Sheik, no Egito; Trípoli, capital da Líbia; Casablanca, em Marrocos; Johannesburgo e Pretória, na África do Sul; Ruthsuru e Goma, na República Democrática do Congo; e Mogadíscio, capital da Somália.

Já as cidades das Américas Central e Sul (com exceção do Brasil), bem como as cidades da Oceania, tiveram juntas cerca de $4 \%$ de representatividade nas fotografias. Da América do Sul, foram postas as fotografias de cidades chilenas Concepción e Santiago e a cidade argentina Buenos Aires. Nas cidades sul-americanas foi ressaltado o contraste socioeconômico existente nessas cidades. As cidades da América Central foram: Havana, em Cuba, com destaque para as representações do governo de Fidel Castro, e Porto Príncipe, no Haiti, com a chamada para os soldados da ONU. As cidades da Oceania foram: 
Sydney e Camberra, na Austrália, e Welington, na Nova Zelândia. Tais cidades se destacaram pelas paisagens naturais.

Em termos de construção do pensamento sobre o ensino de cidade, os jovens que cursaram o ensino médio e tiveram acesso a esses materiais didáticos, possivelmente aprenderam sobre as cidades de vários países, porém de forma limitada. Ademais, nas legendas e nos conteúdos dos livros analisados, há pouca relação de comparação entre as cidades brasileiras e as cidades de outros países, no sentido de apresentar os problemas e soluções para as demandas relativas à mobilidade urbana, ao saneamento básico, à infraestrutura, à cultura, à violência, à cidadania, à política e a outros aspectos igualmente importantes para a atual conjuntura brasileira. Nessa perspectiva, fica inviabiliazada a sistematização de conceitos que compreendam o local e o global e que possam ser pró-ativos.

A apresentação dessas análises sobre os livros didáticos teve como objetivo ampliar o entendimento de como eles podem contribuir para a construção do pensamento geográfico sobre a cidade e o urbano, pois fixam um sentido para os jovens que os terão, muitas vezes, como fontes de pesquisa, estudo e ensino. Nesse pensamento, deixar o aprendizado dos jovens restrito aos livros didáticos pode levar a pouca ou nenhuma compreensão dos conteúdos de forma mais crítica referentes aos significados do espaço físico, social e indentitário. Sem compreender o seu lugar, sua cidade e outros espaços geográficos, os jovens ficam mais expostos ao contexto capitalista e utópico que promove o aumento da desigualdade. Carlos (1999) acrescenta que o sujeito, nesse caso, o jovem, não se reconhece na cidade e nem é reconhecido.

\section{Considerações finais}

Reconhece-se que a sala de aula é um espaço autônomo, e que muitos professores e alunos trazem a esse espaço diferentes discussões e contribuições que incrementam as aulas de geografia. Nessa compreensão, espera-se dos alunos a capacidade de realizarem uma leitura intertextual, haja vista não ser possível dissociar a imagem do texto e do contexto de vivência. Conforme Bakhtin (2006, p. 32), “os signos só emergem, decididamente, do 
processo de interação entre uma consciência individual e uma outra. E a própria consciência individual está repleta de signos". Os signos têm a função de significar e de representar, exercícios necessários quando se observa fotografias.

Ao observar a apresentação das fotografias que tinham a cidade como lugar, nas duas coleções, chega-se à conclusão de que, embora haja contextualizações diferenciadas entre as coleções do livro didático, prevalecem escolhas semelhantes, quando se quer exemplificar alguma citação por fotografias de cidades. Esse fato pode indicar que, em grande parte, os jovens que cursaram o ensino médio utilizando essas coleções, possivelmente, desenvolveram impressões muito próximas entre si das cidades que conheceram pela leitura do livro didático. No entanto, a forma descontextualizada e com pouca ou nenhuma problematização nas legendas pode ter contribuído para que os jovens não tenham construído conceitos adequados sobre as cidades de forma geral. O que pode estigmatizar algumas cidades como pouco e muito desenvolvidas, boas ou ruins para viver, violentas ou pacíficas, belas ou sem atrativos turísticos, enfim, ideias preconceituosas sobre distintos espaços urbanos podem surgir.

Com a observação das fotografias, ficou evidente que muitos espaços do Brasil e do mundo não estão presentes visualmente nos livros didáticos, o que pode significar para os alunos a construção do pensamento de um Brasil mais proeminente e outro Brasil que quase não aparece ou que não precisa estar presente no contexto das discussões em sala de aula. Seguindo o mesmo entendimento, as cidades europeias aparecem mais do que cidades de outros países da América do Sul e da América Central, notadamente pela função econômica e política das cidades, o que acaba subtraindo aspectos importantes, tais como a história, a cultura, a natureza e outros contextos imprescindíveis para a compreensão dos conceitos geográficos, em diferentes escalas.

Ademais, tendo em vista a proposta curricular brasileira, a de que deveria existir uma produção didática mais voltada para a realidade dos alunos, esperava-se que, nos livros didáticos, houvesse mais fotografias de diferentes cidades com realidades semelhantes ou contrastantes, para que os professores problematizassem melhor por comparar e ajudar os alunos na construção dos conceitos geográficos. 
É preciso mostrar as diferentes faces das cidades pelo mundo e reconhecer a necessidade de pensar na importância de compreender as cidades onde estão os alunos e, como esses saberes podem encaminhar aulas que conduzam à aprendizagem significativa. Para Cavalcanti (2008), está nos elementos da dinâmica interna da cidade a condição e a produção das práticas cotidianas e potencialmente importantes para a formação da cidadania. Por meio dessas práticas cotidianas, pode-se pensar em ensinar sobre qualquer cidade.

Desse modo, defende-se que nos livros didáticos haja mais estímulo ao estudo dos lugares e, igualmente, a elaboração de problemáticas sobre os contextos das cidades brasileiras nos distintos espaços urbanos, na compreensão de que o espaço geográfico envolve diferentes escalas de análises. Não se pode construir um pensamento adequado sobre cidade, se o jovem não conhecer o lugar onde vive. Principalmente, porque a maioria dos jovens brasileiros não pode sair de seus lugares para visitar outros, devido aos fatores econômicos, familiares e pessoais. Essa realidade faz com que as fotografias sejam o recurso visual mais próximo que os jovens têm para estabelecer a construção de conhecimentos geográficos, na educação básica. Negar-lhes esse aprendizado resulta na perda do direito à cidade, nos preceitos de Lefebvre (1991). Ademais, como encaminhar propostas de um ensino significativo sobre cidade, se não se começar pelo entendimento da sua própria?

\section{Referências bibliográficas}

ALMEIDA, Lúcia Martins Alves de e RIGOLIN, Tércio Barbosa. Fronteiras da Globalização: O mundo natural e o espaço humanizado. São Paulo, SP: Ática, 2010 a. (v.1). ISBN 978850812920

ALMEIDA, Lúcia Martins Alves de; RIGOLIN, Tércio Barbosa. Fronteiras da Globalização: o espaço geográfico globalizado. Volume: 2. São Paulo, SP: Ática, 2010 b. ISBN 978850812922

ALMEIDA, Lúcia Martins Alves de; RIGOLIN, Tércio Barbosa. Fronteiras da Globalização: o espaço brasileiro natureza e trabalho. Volume: 3. São Paulo, SP: Ática, 2010c. ISBN 978850812924

ALBUQUERQUE, Maria Adailza Martins de. Livros didáticos e currículos de Geografia, Pesquisas e usos: uma história a ser contada. In: Tonini, Ivaine Maria, Goulart, Lígia Beatriz; Martins, Rosa Elisabete Militz Wypyczynki; Castrogiovanni, Antonio Carlos e Kaercher, Nestor André (Orgs.). O ensino de Geografia e suas composições curriculares. Porto Alegre, RS: UFRGS, 2011, p. 155-168. ISBN 9788577060986

BAKHTIN, Mikhail. Marxismo e filosofia da linguagem. 12. ed. São Paulo, SP: Hucitec, 2006. ISBN 9788527100410 
BITTENCOURT, Circe Maria Fernandes. Livro didático e conhecimento histórico: uma História do saber escolar. Tese (Doutorado em Educação). São Paulo, SP: Universidade de São Paulo, 1993.

BRASIL, MINISTÉRIO DA EDUCAÇÃO. Fundo Nacional de Desenvolvimento da Educação. PNLD: Valores de negociação por título - Ensino Médio (regular e educação de jovens e adultos), 2013. Disponível em <http://www.fnde.gov.br/arquivos/file/7771-pnld-2013-valores-de-aquisicao-por-titulo-ensino-medio> Acesso em: 20 set. 2016.

BRASIL. INSTITUTO BRASILEIRO DE GEOGRAFIA E ESTATÍSTICA- IBGE. Ministério do Planejamento. Censo Demográfico de 2010a. Disponível em: ibge.gov.br/Censos/CensoDemografico_2010/Resultados_Gerais da Amostra/Microdados. Acesso em: 20 abr. 2012.

BRASIL. INSTITUTO BRASILEIRO DE GEOGRAFIA E ESTATÍ́STICA. Ministério do Planejamento, Orçamento e Gestão. Aglomerados subnormais Informações territoriais. Censo Demográfico, 2010b. Disponível em https://www.ibge.gov.br. Acesso em 10 set. 2017.

BRASIL. MINISTÉRIO DA EDUCAÇÃO. Secretaria de Educação Básica. Guia de livros didáticos: PNLD 2012: Geografia. Brasília, DF: MEC-SEB, 2011. Disponível em: <http//www.fnde.gov.br/arquivos/category/125-guias? download=5508:pnld-2012-geografia>. Acesso em: 5 out. 2016. ISBN 978857783057.

CARLOS, Ana Fani Alessandri. Apresentando a metrópole na sala de aula. In: Carlos, A. F. A. et al (org). A geografia na sala de aula. São Paulo, SP: Contexto, 1999, p. 79-91. ISBN 9788572441087

CAVALCANTI, Lana de Souza. A Geografia escolar e a cidade. Campinas, SP: Editora Papirus, 2008. ISBN 9878853080874-7.

CAVALCANTI, Lana de Souza. O ensino de geografia na escola. Campinas, SP: Papirus, 2012. (Coleção Magistério: Formação e Trabalho Pedagógico). ISBN 978853080946-1.

CISTERNAS, Nataly Andrea Pérez. O conceito de cidade em Geografia nos livros didáticos do Chile e do Brasil, 2012. Dissertação (Mestrado) - Programa de Pós-Graduação em Geografia, Instituto de Estudos Socioambientais da Universidade Federal de Goiás. Goiânia, GO: 2012.

KIMURA, Shoko. Geografia no ensino básico: questões e propostas. 2. ed. 3. reimpr. São Paulo, SP: Contexto, 2014. ISBN 978857244404-0.

LEFEBVRE, Henri. O direito à cidade. Tradução de Rubens Eduardo Frias. São Paulo, SP: Moraes, 1991. ISBN 9788588208971.

NOVAES, André Reys. O verbal, o visual e a Geografia. In: Ascençâo, Valéria Roque; Valadão, Roberto Célio; Del Gladio, Rogata Soares; Souza, Carla Juscélia de Oliveira. Conhecimentos da Geografia: percursos de formação docente e práticas na educação básica. Belo Horizonte, MG: IGC, 2017, p. 144-164. ISBN 978856196810-6

PORTELA, Mugiany Oliveira Brito. O ensino de cidade na educação básica: conhecimentos geográficos de jovens universitários em Teresina, PI. 2017, 265f. Tese (Doutorado em Geografia). Goiânia,GO: Universidade Federal de Goiás, 2017

SENE, Eustáquio de; MOREIRA, João Carlos. Geografia Geral e do Brasil: espaço geográfico e globalização. 2. ed. reform. São Paulo, SP: Scipione, 2013a. (v. 1.). ISBN 9788526290303

SENE. Eustáquio de; MOREIRA, João Carlos. Geografia Geral e do Brasil: espaço geográfico e globalização. 2. ed. reform. São Paulo, SP: Scipione, 2013b. (v. 2.). ISBN 9788526290327

SENE. Eustáquio de; MOREIRA, João Carlos. Geografia Geral e do Brasil: espaço geográfico e globalização. 2. ed. reform. São Paulo, SP: Scipione, 2013c. (v. 3.) . ISBN 978852629133

TONINE, Ivaine Maria. Livro didático: textualidades em rede? In: Tonini, Ivaine Maria, Goulart, Lígia Beatriz; Martins, Rosa Elisabete Militz Wypyczynki; Castrogiovanni, Antonio Carlos e Kaercher, Nestor André (Org.). $O$ ensino de Geografia e suas composições curriculares. Porto Alegre, RS: UFRGS, 2011, p.145-168. ISBN 9788577060986

VYGOTSKY, Lev Semenovich. A construção do pensamento e da Linguagem. Tradução de Paulo Bezerra. São Paulo, SP: Martins Fontes, 2000. ISBN 853361361-X 